\title{
A phase I trial of the HIV protease inhibitor nelfinavir in adults with solid tumors
}

Gideon M. Blumenthal' ${ }^{1}$, Joell J. Gills ${ }^{3}$, Marc S. Ballas ${ }^{1}$, Wendy B. Bernstein ${ }^{1}$, Takefumi Komiya ${ }^{1}$, Roopa Dechowdhury ${ }^{1}$, Betsy Morrow ${ }^{1}$, Hyejeong Root $^{1}$, Guinevere Chun ${ }^{1}$, Cynthia Helsabeck ${ }^{1}$, Seth M. Steinberg ${ }^{2}$, Jaclyn LoPiccolo ${ }^{1}$, Shigeru Kawabata ${ }^{3}$, Erin R. Gardner ${ }^{1}$, William D. Figg ${ }^{1}$, Phillip A. Dennis ${ }^{3}$

${ }^{1}$ Medical Oncology Branch, National Cancer Institute, Bethesda, MD

${ }^{2}$ Biostatistics and Data Management Section, National Cancer Institute, Bethesda, MD

${ }^{3}$ Department of Oncology, Johns Hopkins School of Medicine, Baltimore, MD, USA

Correspondence to:

Dr. Phillip A. Dennis, e-mail: pdennis@jhmi.edu

Key words: Nelfinavir, phase I clinical trial, AKT, endoplasmic reticulum stress, neuroendocrine

Received: June 30, 2014

Accepted: August 28, 2014

Published: September 06, 2014

\section{ABSTRACT}

Nelfinavir is an HIV protease inhibitor being repurposed as an anti-cancer agent in preclinical models and in small oncology trials, yet the MTD of nelfinavir has not been determined. Therefore, we conducted a Phase Ia study to establish the maximum tolerated dose (MTD) and dose limiting toxicities (DLT) of nelfinavir in subjects with advanced solid tumors. Adults with refractory cancers were given oral nelfinavir twice daily with pharmacokinetic and pharmacodynamic analyses. Twenty-eight subjects were enrolled. Nelfinavir was generally well tolerated. Common adverse events included diarrhea, anemia, and lymphopenia, which were mostly mild. The DLT was rapid-onset neutropenia that was reversible. The MTD was established at $3125 \mathrm{mg}$ twice daily. In an expansion cohort at the MTD, one of $11(9 \%)$ evaluable subjects had a confirmed partial response. This, plus two minor responses, occurred in subjects with neuroendocrine tumors of the midgut or pancreatic origin. Thirty-six percent of subjects had stable disease for more than 6 months. In peripheral blood mononuclear cells, Nelfinavir inhibited AKT and induced markers of ER stress. In summary, nelfinavir is well tolerated in cancer patients at doses $\mathbf{2 . 5}$ times the FDAapproved dose for HIV management and showed preliminary activity in tumors of neuroendocrine origin.

\section{INTRODUCTION}

The success of molecularly targeted agents such as imatinib, erlotinib and vemurafenib established the era of personalized medicine in oncology. Yet, for a majority of cancer patients there remains an urgent need for more effective, better-tolerated drugs. The rising price of new oncology drugs [1], and the increasing length and cost of drug development [2], have caused growing concern within the government, academia and pharmaceutical industry. One means of hastening drug development and reducing costs is to identify new indications for already approved drugs, referred to as 'repositioning' or 'repurposing' [3, 4]. Repurposing established drugs may eliminate the years of pre-clinical pharmacology, toxicology and chemistry normally required for New Molecular Entities, and has successfully delivered drugs previously approved for non-cancer indications such as thalidomide [5,6] into the clinic, and itraconazole [7] and chloroquine [8] into oncology clinical trials.

We hypothesized that nelfinavir could be repurposed as an anti-cancer agent because of its ability to inhibit the PI3K/Akt/mTOR pathway in preclinical studies. Activation of the PI3K/ Akt/mTOR pathway is an important feature in many cancers, and inhibitors of this pathway have been developed as anti-cancer drugs [9, 10]. Inhibition of this pathway can induce toxicities such as dyslipidemia, hyperglycemia, and insulin resistance [11-13], all of which are commonly observed in 
patients treated with HIV protease inhibitors. This raised the possibility that HIV protease inhibitors might have unappreciated clinical activity as inhibitors of this pathway. Secondly, preclinical studies have shown that nelfinavir has anti-cancer properties. For example, nelfinavir inhibits the PI3K/AKT/mTOR pathway, inhibits cancer cell proliferation, and induces endoplasmic reticulum stress, autophagy and apoptosis [14] at concentrations that have been observed in HIV patients.

Given that a maximum tolerated dose (MTD) of nelfinavir was never established in early HIV clinical trials because dose escalation stopped with suppression of HIV RNA viral load $[15,16]$, we conducted a Phase Ia, dose escalation study in subjects with advanced solid tumors to determine the MTD and dose limiting toxicities (DLT) of nelfinavir in cancer patients.

\section{RESULTS}

Twenty-eight subjects with a wide variety of tumor histologies and tissues of origin were enrolled between 2007 and 2010 and are included in the analysis (Table 1). The most common cancers were colorectal adenocarcinoma (17.9\%), small cell lung cancer $(14.3 \%)$, non-small cell lung cancer $(14.3 \%)$, and neuroendocrine tumor of the midgut or pancreas $(14.3 \%)$. Subjects were heavily pre-treated, with $42.9 \%$ having received three or more prior systemic

Table 1: Patient Demographics all Treated Patients $(n=28)$

\begin{tabular}{|c|c|c|}
\hline Demographic & Number & $\%$ \\
\hline \multicolumn{3}{|l|}{ Sex } \\
\hline Male & 19 & 67.9 \\
\hline Female & 9 & 32.1 \\
\hline \multicolumn{3}{|l|}{ Age (years) } \\
\hline Median & 63 (range 24.8-84.8) & \\
\hline \multicolumn{3}{|l|}{ Race } \\
\hline White & 24 & $85.7 \%$ \\
\hline Black & 4 & $14.3 \%$ \\
\hline \multicolumn{3}{|l|}{ Cancer Type } \\
\hline Colorectal & 5 & $17.9 \%$ \\
\hline Lung (small cell) & 4 & $14.3 \%$ \\
\hline Lung (non small cell) & 4 & $14.3 \%$ \\
\hline Carcinoid/ NET & 4 & $14.3 \%$ \\
\hline Thyroid & 3 & $10.7 \%$ \\
\hline Renal & 2 & $7.1 \%$ \\
\hline Adenoid Cystic & 2 & $7.1 \%$ \\
\hline Other (sarcoma, head and neck, pancreatic adeno, prostate) & 4 & $14.3 \%$ \\
\hline \multicolumn{3}{|l|}{ Prior Chemotherapy Regimens (range 0-8) } \\
\hline 0 & 3 & $10.7 \%$ \\
\hline $1-2$ & 13 & $46.4 \%$ \\
\hline$>3$ & 12 & $42.9 \%$ \\
\hline \multicolumn{3}{|l|}{ ECOG PS at screening } \\
\hline 0 & 6 & $21.4 \%$ \\
\hline 1 & 16 & $57.1 \%$ \\
\hline 2 & 6 & $21.4 \%$ \\
\hline
\end{tabular}


regimens. The majority of subjects (78.5\%) had ECOG performance status of 1 or 2 .

Twenty-four subjects were evaluable for safety, while four subjects withdrew consent for non-toxicity related issues prior to completion of cycle 1 and were replaced. These subjects were considered non-evaluable for the following reasons: one for progression of disease (DL2), two due to patient preference (DL1 and DL4, respectively), and one for protocol deviation (DL4). The numbers of subjects evaluable for toxicity at each dose level were: three each at DL1 (1250 mg bid), DL2 (1875 mg bid), DL3 (2500 mg bid), and DL5 (3750 mg bid), and twelve patients at DL4 (3125 mg bid).

\section{Safety}

Subjects evaluable for toxicity $(\mathrm{n}=24)$ received 119 courses at five different dose levels. The median number of cycles was 2 (range 1-35 cycles). No cumulative toxicities were observed. The dose-limiting toxicity was grade 4 neutropenia, which occurred in two of three patients at dose level 5 (Table 2). Nelfinavir-induced neutropenia differed from that observed with conventional cytotoxic chemotherapy in that it was characterized by rapid onset ( $\leq 3$ days), followed by rapid recovery after discontinuation of drug ( $\leq 3$ days), and a similar rapid decline with re-challenge. A representative image of a subject's peripheral blood smear that experienced nelfinavir-induced neutropenia (with acanthocytosis) is shown in Figure 1.

The most common treatment-related adverse events (AE) observed in cycle 1 included diarrhea (50\%), anemia (41.7\%), lymphopenia (41.7\%), fatigue (20.8\%), and hypoalbuminemia (20.8\%) (Table 2). Rates of AEs attributable to nelfinavir increased with dose escalation, but clinically significant grade 3 or 4 AEs were rare. Grade 3 to 4 AEs of interest include two cases of grade 4 neutropenia at DL5, one case of grade 3 diarrhea at DL4,

Table 2: Treatment-related Adverse Events in cycle 1

\begin{tabular}{|c|c|c|c|c|c|c|c|c|c|c|c|}
\hline & \multicolumn{2}{|c|}{ DL1 $(n=3)$} & \multicolumn{2}{|c|}{ DL2 $(n=3)$} & \multicolumn{2}{|c|}{$\operatorname{DL3}(n=3)$} & \multicolumn{2}{|c|}{ DL4 $(n=12)$} & \multicolumn{2}{|c|}{$\operatorname{DL5}(n=3)$} & \multirow{2}{*}{$\begin{array}{c}\text { Total } \\
\text { N (\%) }\end{array}$} \\
\hline & Gr 1-2 & Gr 3-4 & Gr 1-2 & Gr 3-4 & Gr 1-2 & Gr 3-4 & Gr 1-2 & Gr 3-4 & Gr 1-2 & Gr 3-4 & \\
\hline \multicolumn{12}{|l|}{ General } \\
\hline Fatigue & & & 1 & & & & 3 & & 1 & & $5(20.8)$ \\
\hline Dehydration & & & & & & & 1 & & 1 & & $2(8.3)$ \\
\hline \multicolumn{12}{|l|}{ GI } \\
\hline Heartburn & & & & & & & 1 & & & & $1(4.2)$ \\
\hline Diarrhea & & & 2 & & 1 & & 5 & 1 & 3 & & $12(50.0)$ \\
\hline Nausea & & & & & & & 2 & & & & $2(8.3)$ \\
\hline Bloating/ & & & & & & & 2 & & 1 & & $3(12.5)$ \\
\hline Anorexia & & & & & & & & & 1 & & $1(4.2)$ \\
\hline Belching & & & & & & & 1 & & & & $1(4.2)$ \\
\hline Abdominal pain & & & & & & & 1 & & & & $1(4.2)$ \\
\hline Flatulence & & & & & & & 1 & & & & $1(4.2)$ \\
\hline \multicolumn{12}{|l|}{ Metabolic } \\
\hline ALT increase & & & 1 & & 1 & & 2 & & 1 & & $5(20.8)$ \\
\hline Cholesterol increase & & & & & & & 3 & & & & $3(12.5)$ \\
\hline Hyponatremia & & & & & & & 1 & & 1 & & $2(8.3)$ \\
\hline Hyperglycemia & & & & & 2 & & 2 & & & & $4(16.7)$ \\
\hline Hypothyroid & & & & 1 & & & & & & & $1(4.2)$ \\
\hline Hypokalemia & & & & & & & 1 & & & & $1(4.2)$ \\
\hline Hypophosphatemia & & & & & & & & & 1 & & $1(4.2)$ \\
\hline
\end{tabular}

(Continued) 


\begin{tabular}{|c|c|c|c|c|c|c|c|c|c|c|c|}
\hline & \multicolumn{2}{|c|}{ DL1 $(n=3)$} & \multicolumn{2}{|c|}{ DL2 $(n=3)$} & \multicolumn{2}{|c|}{$\operatorname{DL3}(n=3)$} & \multicolumn{2}{|c|}{ DL4 $(n=12)$} & \multicolumn{2}{|c|}{$\operatorname{DL5}(n=3)$} & \multirow{2}{*}{$\begin{array}{c}\text { Total } \\
\text { N (\%) }\end{array}$} \\
\hline & Gr 1-2 & Gr 3-4 & Gr 1-2 & Gr 3-4 & Gr 1-2 & Gr 3-4 & Gr 1-2 & Gr 3-4 & Gr 1-2 & Gr 3-4 & \\
\hline Hyperkalemia & & & & & & & 2 & & 1 & & $3(12.5)$ \\
\hline Hypoalbuminemia & & & & & & & 3 & & 2 & & $5(20.8)$ \\
\hline \multicolumn{12}{|l|}{ Hematologic } \\
\hline Anemia & & & & & & & 9 & & 1 & & $10(41.7)$ \\
\hline Thrombocytopenia & & & & & 1 & & & & 1 & & $2(8.3)$ \\
\hline Leukopenia & & & & & & & 1 & 1 & & 2 & $4(16.7)$ \\
\hline Neutropenia & & & & & 1 & & 2 & & & 2 & $5(20.8)$ \\
\hline Lymphopenia & & & & & & & 6 & 2 & 2 & & $10(41.7)$ \\
\hline \multicolumn{12}{|l|}{ Other } \\
\hline Depression & & & & & & & 1 & & & & $1(4.2)$ \\
\hline Palpitations & & & & & & & & & 1 & & $1(4.2)$ \\
\hline Insomnia & & & & & & & & & 1 & & $1(4.2)$ \\
\hline
\end{tabular}

and a grade 3 hypothyroidism at DL2. The hypothyroid event was due to an interaction between nelfinavir and levothyroxine, which has also been reported in HIV patients taking protease inhibitors and thyroid replacement therapy [17]. Following this event, the protocol was amended to extend the interval between administration of nelfinavir and levothyroxine to at least three hours apart, and no further hypothyroid events were noted in patients taking thyroid replacement therapy.

\section{Pharmacokinetics}

First dose nelfinavir pharmacokinetics were evaluable in 26 subjects across five dose levels, ranging from 1250 to $3750 \mathrm{mg}$ (Supplemental table 1). Nonlinear pharmacokinetics were observed following the first dose of oral nelfinavir (Figure 2A). No increase in overall nelfinavir exposure or maximal plasma concentration was seen at doses in excess of $1875 \mathrm{mg}$. However, variability in exposure was substantially higher at higher dose levels.

Steady state (C2D1) nelfinavir pharmacokinetics were evaluable for 17 subjects (Supplemental Table 2). No significant association between dose and $\mathrm{Cmax}, \mathrm{Cmin}$ and AUC was observed ( $p=0.09$ to 0.63 ) (Figure 2B), further exemplifying the non-linear pharmacokinetics of this agent. Nonetheless, there was a trend towards increasing trough concentrations (regardless of morning or evening) with increasing dose.

The pharmacokinetics of midazolam, a phenotyping probe for CYP3A4 activity, were evaluated prior to the start of treatment with nelfinavir (C1D-2) and at steady state (C1D20). Complete, paired pharmacokinetic data was evaluable for 19 subjects. A significant decrease in midazolam clearance was observed on day 20 , as compared to pre-nelfinavir $(\mathrm{p}<0.001$; Figure $2 \mathrm{C})$. Similarly, a significant increase in exposure and half-life were noted ( $<<0.05$ for each; data not shown).

\section{Pharmacodynamics}

Surrogate biomarkers in PBMCs collected at baseline, D7 and D42 were analyzed by immunoblotting. These biomarkers included evaluation of Akt activation (P-Akt S473) and markers of ER stress (P-EIF2 alpha S51, ATF3 or CHOP). There were no biomarker changes noted in PBMCs collected from subjects at baseline to either DL1 or DL2. Samples from 1 out of 3 subjects in DL3 showed a decrease in P-AKT S473 or an increase in EIF2 alpha S51 phosphorylation. At DL4, 45\% of subject PBMCs taken after 7 or 42 days of nelfinavir treatment showed a decrease in P-AKT S473 and the same percentage showed an increase in P-EIF2 alpha S51, indicative of endoplasmic reticulum (ER) stress. In addition, $27 \%$ of samples showed an increase in ATF3 and/or CHOP, also suggestive of ER stress. Within DL4, 3 subjects showed changes in 3 of 4 biomarkers evaluated, two examples of which are shown (Figure 3). The rest of the PBMC samples from DL4 subjects showed either change in a single biomarker, or no change from baseline in the 4 biomarkers evaluated.

\section{Antitumor Activity}

Twenty-one subjects had an on-study tumor assessment and thus were evaluable for response, 


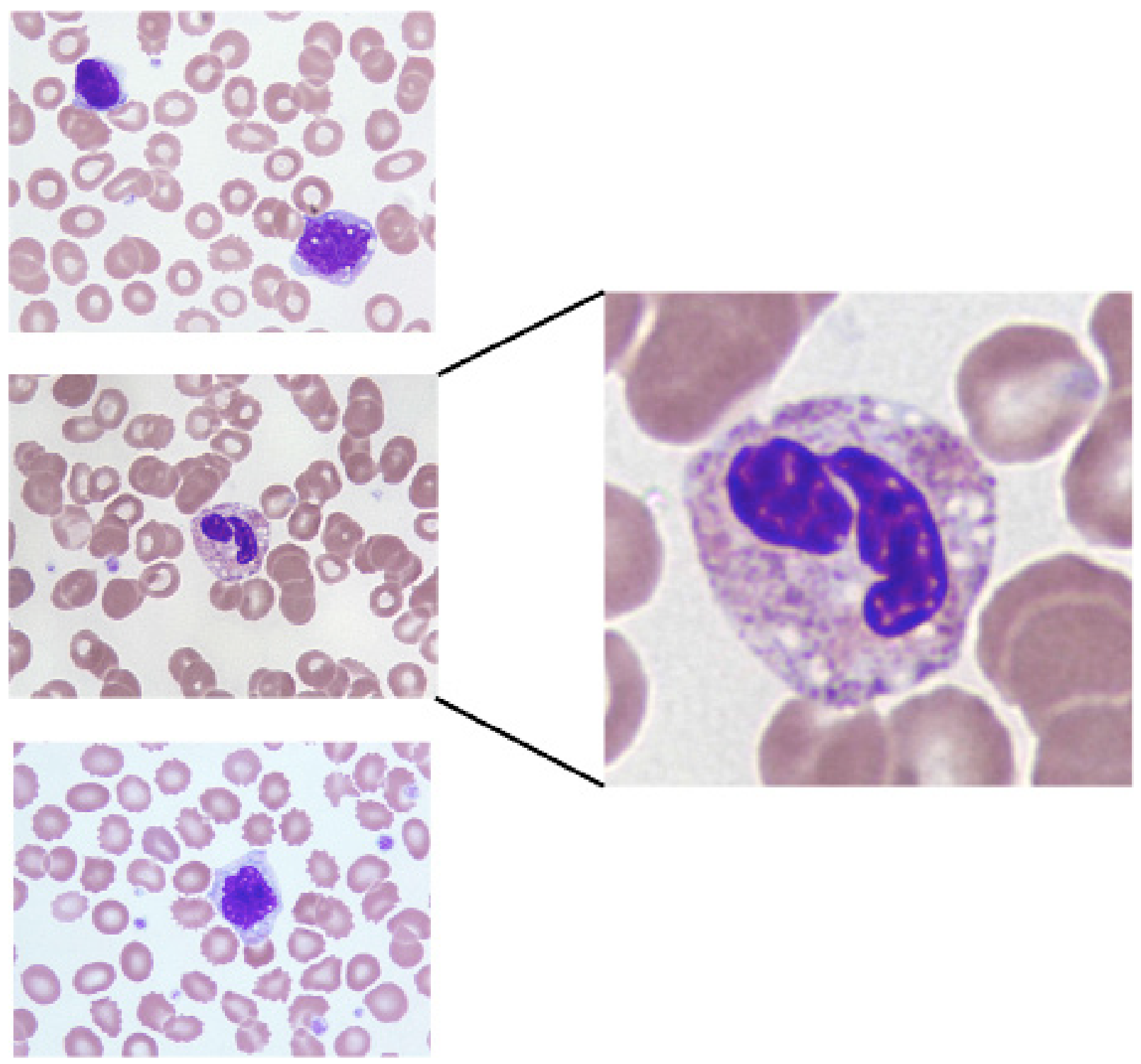

Figure 1: Blood smear showing vacuolated monocytes and neutrophil from a patient that experienced DLT on nelfinavir DL5.

eleven in the expansion cohort at the $3125 \mathrm{mg}$ bid MTD, and ten at all other dose levels (Table 3). A patient with progressive neuroendocrine tumor (NET) of the midgut and carcinoid syndrome had a partial response at the MTD (subject 28, Table 3), yielding a 9.1\% ORR at the MTD and a $4.8 \%$ ORR in the overall population. Minor responses (defined as tumor regressions < 30\%) were observed in three additional subjects, all of whom were treated at the MTD. Two of these patients had NET of the midgut or pancreas, (subjects 18 and 26) and one had small cell lung cancer (subject 24, Table 3) although this response was potentially confounded by radiation to the target lesion completed months prior to enrollment. Four subjects treated at the $3125 \mathrm{mg}$ BID MTD (36\%) who had progressed prior to study entry, remained on study for 8 months or more. A subject with adenoid cystic carcinoma was on study with stable disease for 11 months. Two of the subjects with NET of the midgut were on study for at least 8 months, and the subject that achieved a PR remained on study for 23.5 months and received nelfinavir off study for an additional six months with stable disease, prior to disease progression in the liver and pelvis (Figure 4). A subject with MEN1 syndrome and pancreatic NET was on study for 12.4 months. In the responders with NET that had carcinoid syndrome with flushing and diarrhea, nelfinavir improved these symptoms within 7 days, which was associated with transient decreases in levels of circulating chromogranin, synaptophysin, and/or urinary 5-HIAA. 

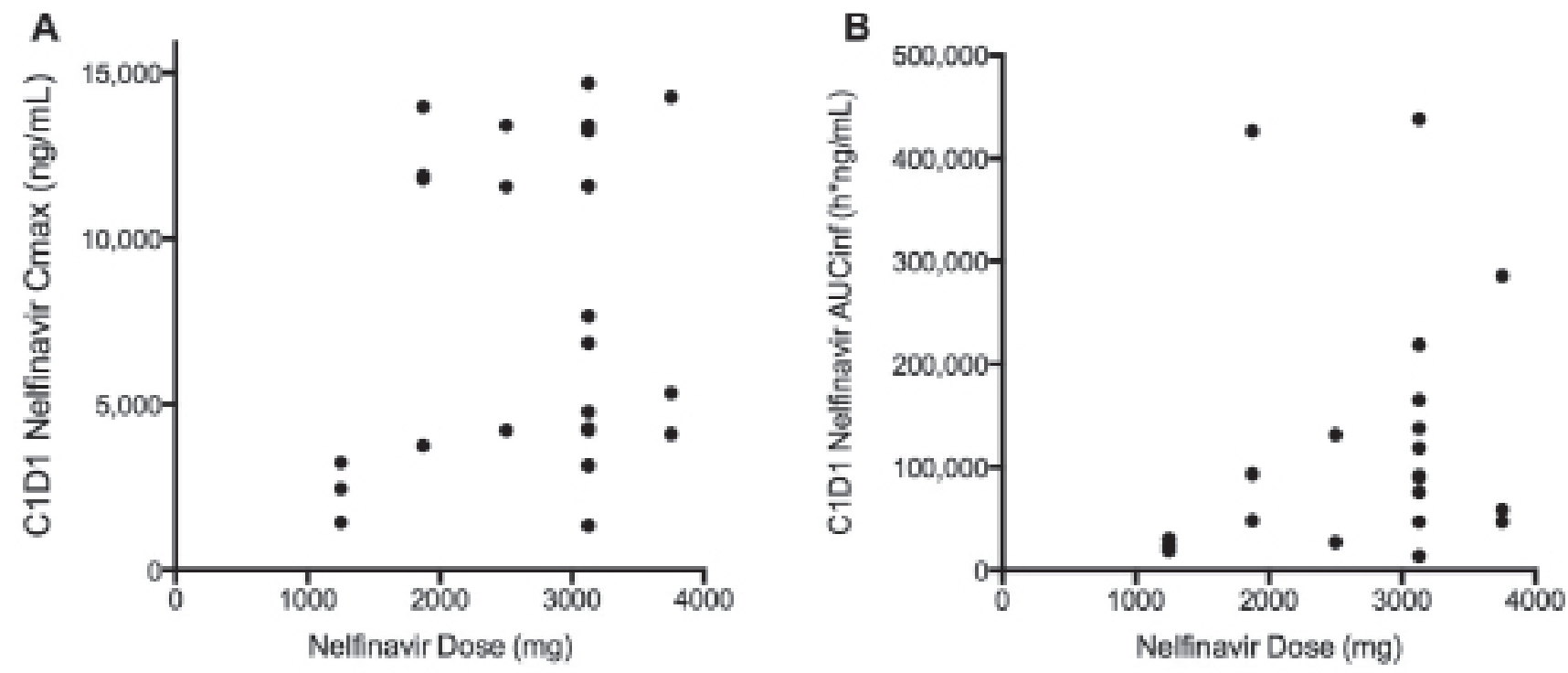

Figure 2A: C1D1 Nelfinavir (A) Cmax and (B) AUCinf, by dose. Each dot represents an individual patient.
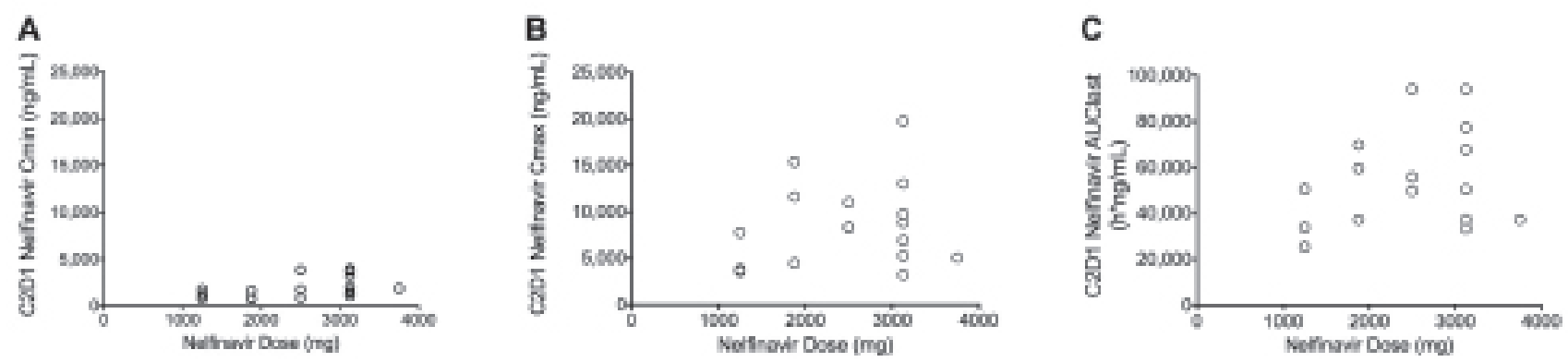

Figure 2B: C2D1 Nelfinavir (A) Cmin (immediately prior to dose administration), (B) Cmax and (C) AUClast, by dose. Each dot represents an individual patient.

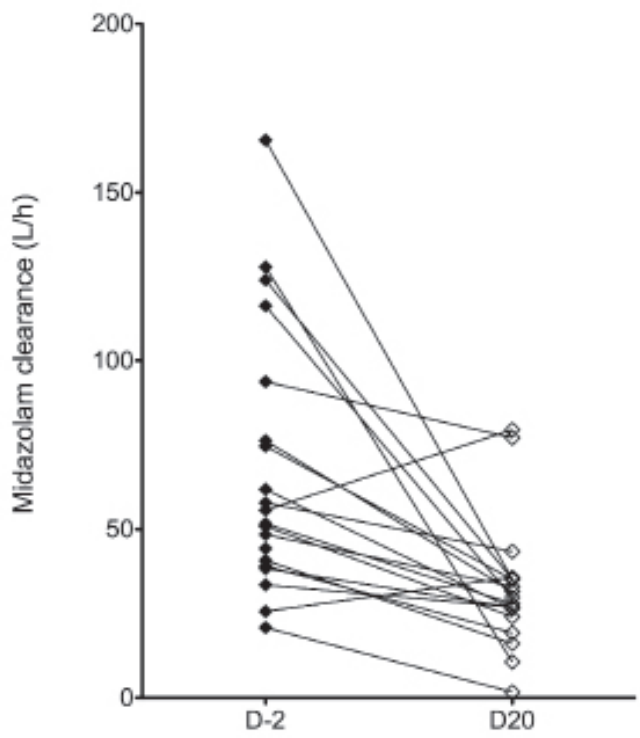

Figure 2C: Pairwise comparison of midazolam clearance prior to the start of nelfinavir treatment (D-2) and at nelfinavir steady-state (D20). 


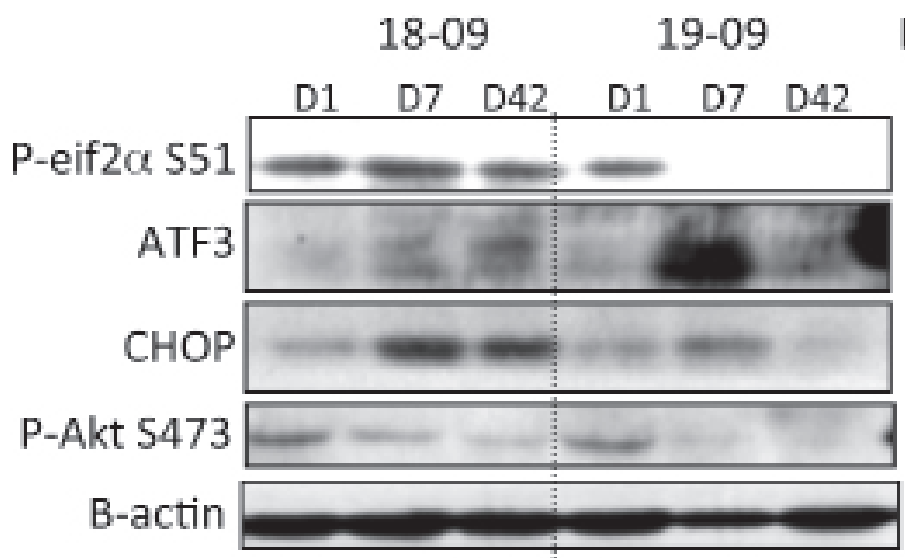

Figure 3: PI3K/AKT inhibition and ER stress pathway induction by nelfinavir in PBMCs of two cancer patients at the MTD.

Table 3: Evaluable subject response and duration of therapy on Nelfinavir

\begin{tabular}{|c|c|c|c|c|c|}
\hline Subject & Age & Diagnosis & Dose Level & $\begin{array}{l}\text { Best } \\
\text { Response }\end{array}$ & $\begin{array}{l}\text { Duration of } \\
\text { therapy (mos.) }\end{array}$ \\
\hline 1 & 62 & SCLC & $1250 \mathrm{mg}$ BID & PD & 1.4 \\
\hline 3 & 63 & SCLC & & PD & 1.4 \\
\hline 4 & 77 & SCLC & & PD & 1.4 \\
\hline 5 & 63 & Anaplastic Thyroid & 1875 mg BID & PD & 1.4 \\
\hline 7 & 62 & Differentiated Thyroid & & PD & 2.8 \\
\hline 8 & 65 & NSCLC & & SD & 3.5 \\
\hline 9 & 24 & Colorectal & $2500 \mathrm{mg}$ BID & PD & 1.4 \\
\hline 10 & 75 & Pancreatic Adenocarcinoma & & PD & 2.8 \\
\hline 11 & 71 & NSCLC & & SD & 4.1 \\
\hline 12 & 59 & Differentiated thyroid & $3125 \mathrm{mg}$ BID & PD & 2.1 \\
\hline 14 & 48 & Renal Cell Cancer & & PD & 1.4 \\
\hline 17 & 64 & Adenoid Cystic & & SD & 11.0 \\
\hline 18 & 60 & Neuroendocrine tumor & & MR & 8.3 \\
\hline 19 & 62 & Colorectal & & SD & 4.1 \\
\hline 23 & 64 & Prostate & & PD & 1.0 \\
\hline 24 & 61 & SCLC & & MR & 2.8 \\
\hline 25 & 46 & Colorectal & & SD & 2.8 \\
\hline 26 & 65 & Neuroendocrine tumor & & MR & 12.4 \\
\hline 27 & 67 & Neuroendocrine tumor & & SD & 3.5 \\
\hline 28 & 45 & Neuroendocrine tumor & & PR & 23.5 \\
\hline 21 & 49 & Adenoid Cystic & $3750 \mathrm{mg}$ BID & PD & 1.4 \\
\hline
\end{tabular}

$\mathrm{SCLC}=$ small cell lung cancer; $\mathrm{NSCLC}=$ non small cell lung cancer; $\mathrm{BID}=$ twice daily; $\mathrm{PD}=$ progressive disease; $\mathrm{SD}=$ stable disease; $\mathrm{MR}=$ minor response; $\mathrm{PR}=$ partial response 


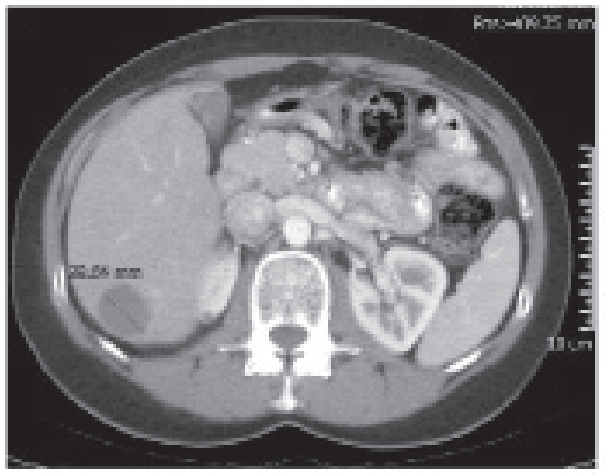

Baseline

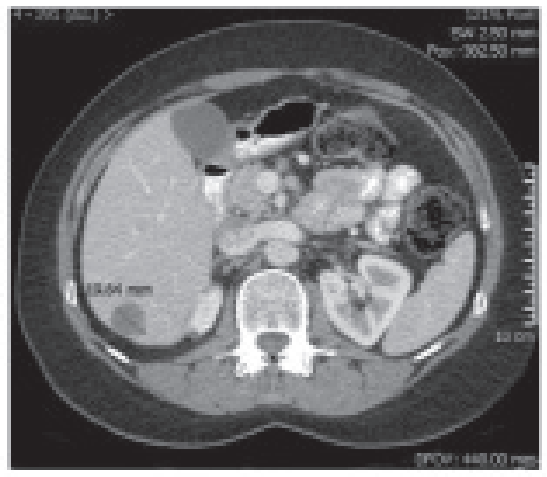

13 months

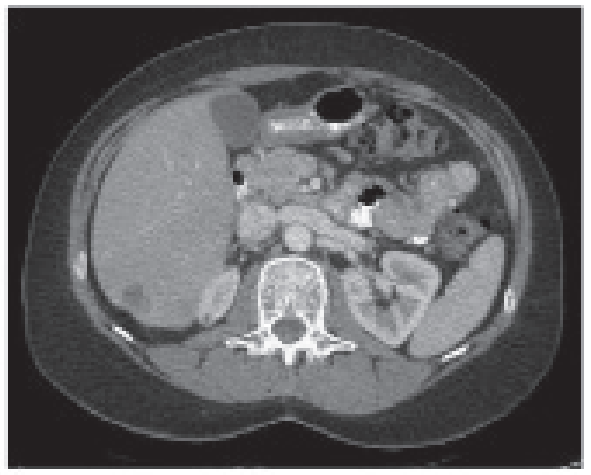

31 months

Figure 4: Serial CT images from a subject who achieved a sustained PR response on nelfinavir in target lesion in liver.

\section{DISCUSSION}

Nelfinavir has pleiotropic mechanisms in cancer cells including induction of ER stress, apoptosis and autophagy [14], inhibition of angiogenesis [18], proteasome activity [19], AKT [14], HIF1alpha [20], site-2 protease [21], and hsp90 [22], as well as radiation sensitization [23]. The fact that the crucial mechanism(s) in vivo are not known, combined with the lack of knowledge regarding MTD, informed our decision to perform a dose escalation phase I trial. This study establishes the maximal tolerated dose of nelfinavir in patients with mixed-cancer subtypes at 3125 mg BID, and is the first to describe potential benefit in patients with neuroendocrine tumors. Nelfinavir was well tolerated. At the $3125 \mathrm{mg}$ BID MTD dose, patients did not experience adverse reactions typically associated with either cytotoxic chemotherapy, tyrosine kinase inhibitors, or the Akt/mTOR pathway (such as rash, mucositis and hyperglycemia), nor did they experience significant diarrhea as has been reported with nelfinavir in HIV patients. These observations are consistent with the results of a Phase I trial of nelfinavir in liposarcoma patients where the MTD was not reached; however, auto-induction was noted at the highest dose evaluated (4125 mg BID), and a Phase II trial using a 3,000 mg BID dose is planned [24].

The dose limiting toxicity of nelfinavir is neutropenia, and a blood smear from a patient that experienced this DLT showed the presence of cytoplasmic vacuoles in their neutrophils and monocytes, as well as acanthocytosis. The presence of cytoplasmic vacuoles is similar in appearance to the vacuoles observed in cancer cell lines treated with nelfinavir in vitro [14], and the red blood cell morphology is similar that observed in GADD34 knockout mice [25] that have increased levels of ER stress, because GADD34 dephosphorylates eif2alpha [26] and thereby reverses translation inhibition under stress conditions. Cytosolic vacuolization, plus the fact the neutropenia was rapidly reversible, suggests this toxicity may be due to induction of ER stress in mature cellular lineages rather than affecting bone marrow precursor cells. Unexpectedly, several of the common toxicities of protease inhibitors observed in HIV patients, such as central lipodystrophy, dyslipidemia, or hyperglycemia were not frequently observed in our study population.

One patient with NET of the midgut experienced a partial response and two other patients with NET had minor responses and prolonged stable disease after documented progression prior to enrollment. Recently, a trial with the mTOR inhibitor everolimus demonstrated efficacy in pancreatic NET, driven mainly by stable disease [27]. It is not known whether nelfinavir decreases tumor growth in neuroendocrine tumors by inhibition of the PI3K/AKT/mTOR pathway, which can be activated in pancreatic neuroendocrine tumors by mutations in the mTOR pathway [28], or by causing cytotoxicity due to ER dysfunction and protein misfolding in a secretory tumor with high rates of protein synthesis, bioactive hormone release, and turnover.

The MTD of nelfinavir as a single agent in solid tumors is $3125 \mathrm{mg}$ bid, which is 2.5 fold over the doses typically used in HIV patients. The PK data showed potential non-linearity above doses of 1875 to $2500 \mathrm{mg}$. These data correspond with nelfinavir PK in liposarcoma patients where the authors found nonlinearity above $3000 \mathrm{mg}$ bid [24], and suggests that dose escalation of nelfinavir to the $3125 \mathrm{mg}$ bid MTD in future single agent or combination studies in cancer may not be warranted. Although our results and the results in liposarcoma suggest that nelfinavir has activity as a single agent, nelfinavir may have additional efficacy when combined with different types of agents. For example, nelfinavir has been combined with bortezomib in preclinical studies to exploit proteotoxicity as a mechanism of cancer cell death [29]. Nelfinavir can also be safely combined with other chemotherapies as well as radiation, because Phase I trials that used the FDA-approved dose of nelfinavir with concurrent chemoradiation in pancreatic cancer [30], rectal [31] and NSCLC [32] have been reported. 
In conclusion, nelfinavir has great promise for repositioning as an anti-cancer agent, as its DLT is readily reversible, is otherwise well tolerated, and has preliminary signs of anti-tumor activity, especially in patients with NET of midgut and pancreatic origin. Future trials are planned.

\section{METHODS}

\section{Ethics}

The National Cancer Institute (NCI) intramural Institutional Review Board (IRB) approved the study prior to its initiation. Subjects provided written informed consent for their participation.

\section{Study Design}

This single institution, open-label, Phase Ia dose escalation study was performed to establish the MTD and DLT of nelfinavir in subjects with advanced refractory solid tumors. The study used a modified Fibonacci scheme, in which cohorts of three to six subjects were entered at each dose level until two patients developed DLT. If two or more subjects encountered DLT, then the MTD was exceeded. The MTD was defined as the dose level at which less than 2 of 6 subjects experienced DLT. Each cycle lasted 21 days. Up to 6 additional patients were allowed to be enrolled at the MTD in order to better establish potential rates of toxicity.

\section{Subject Selection}

Subjects needed to have histologically confirmed advanced cancer that had relapsed following or progressed through standard therapy, Eastern Cooperative Oncology Group (ECOG) performance status 0 to 2; expected survival of at least 3 months, adequate hematologic and renal function; total bilirubin less than the upper limit of normal (ULN) and serum AST and ALT $<2.5 \times$ ULN, stable treated brain metastases, no uncontrolled intercurrent illness, no strong CYP3A4 inhibitors or inducers, no escalating doses of corticosteroids, no pregnant or lactating women, and no chemotherapy or radiation within 28 days.

\section{Clinical Care of Patients}

Physical examinations, toxicity assessments and laboratory analyses were conducted weekly during cycle 1 and then every three weeks beginning cycle 2 . An electrocardiogram was performed every cycle, and restaging scans were performed at baseline and every two cycles thereafter. Subjects remained on study until disease progression (as determined by RECIST), severe toxicity, or individual choice.

\section{Drug Administration}

Nelfinavir was supplied by the Clinical Pharmacy at the NIH Warren Grant Magnuson Clinical Center (Bethesda, MD). Nelfinavir mesylate $625 \mathrm{mg}$ tablets were dispensed.

\section{Subject Accrual}

The starting dose of nelfinavir was the FDAapproved dose in HIV patients of $1250 \mathrm{mg}$ twice daily, which comprised dose level (DL) 1. Dose escalation proceeded in $625 \mathrm{mg}$, twice-daily increments (DL2: 1875 mg, DL3: 2500 mg, DL4: 3125 mg, DL5: 3750 mg, DL6: $4375 \mathrm{mg})$.

\section{DLTs}

Toxicity was graded according to the National Cancer Institute Common Toxicity Criteria, version 3.0. DLT was defined as any drug-related (possible, probable, definite) grade 4 neutropenia, grade 3 or 4 neutropenia accompanied by fever 100.4 or greater, grade 3 hypercholesterolemia, grade 3 diarrhea, or any other grade 4 adverse event.

\section{Pharmacokinetic Methods}

To determine CYP3A4 phenotype, a single $3 \mathrm{mg}$ oral dose of midazolam hydrochloride, a CYP3A4 substrate, was administered at day -2 (2 days prior to commencing nelfinavir) and again at steady state (cycle 1 day 20). Serial venous blood samples were collected at 15, 30, 60, 120, 180,240 , and 300 minutes following administration of midazolam. Nelfinavir pharmacokinetics (PK) were obtained after single dose administration, cycle 1 day 1 , and again at steady state, cycle 2 day 1 . Serial venous blood samples were collected pre-dose and at 1, 2, 3, 4, 5, 6 and 12 hours after administration. Plasma concentrations of midazolam and nelfinavir were determined with a validated assay employing high performance liquid chromatography (HPLC) with mass spectrometric detection. Noncompartmental pharmacokinetic analyses were performed with WinNonlin 5.2 (Pharsight). Individual concentration-time profiles were constructed for each patient, course and drug resulting in four profiles per patient (two each for midazolam and nelfinavir). The maximum plasma concentration (Cmax) and the time of maximum plasma concentration (Tmax) were the observed values. Drug exposure was estimated using the area under the concentration-time curve (AUC). The area under the concentration-time curve (AUC) from time zero to the time of the final quantifiable sample (AUClast) was calculated using the linear trapezoidal method. The area under the concentration-time curve from time zero to infinity $\left(\mathrm{AUC}_{\mathrm{inf}}\right)$ was calculated by extrapolation, using the terminal rate constant from the last measurable concentration. 


\section{Pharmacodynamic Analysis}

Peripheral blood mononuclear cells (PBMCs) were collected at baseline, and then twice after starting nelfinavir: cycle 1 day 7 and cycle 1 day 42. Levels of P-AKT S473, P-EIF2 alpha S51, ATF3 and CHOP in PBMCs before and after nelfinavir were analyzed by immunoblotting. Blood was collected in Vacutainer CPT collection tubes with sodium heparin (BD Biosciences cat\# 362753) and mononuclear cells were isolated as per the manufacturer's instructions. PBMCs were washed with PBS and lysed in 2X LSB buffer [33], aliquotted and stored at $-80^{\circ} \mathrm{C}$. For analysis, equal amounts of protein per sample were run on 10-12\% SDS-PAGE gels, then transferred onto nitrocellulose membranes. Membranes were blocked in $5 \%$ milk in TBS $+0.1 \%$ tween (TBST) and incubated with primary antibody diluted in 5\% BSA in TBST at 4 degrees overnight. The next day membranes were washed, incubated with HRP-linked secondary antibody and developed using ECL chemiluminescent reagent (GE Healthcare) and X-ray film as per the manufacturers instructions. The amount of P-AKT S473, P-EIF2 alpha S51, ATF3 or CHOP in the PBMCs at C1D7 and C1D42 were compared against a baseline sample for each patient, (prior to receiving nelfinavir). Antibodies against P-AKT S473 \#4060, P-EIF2 alpha S51 \#3398 and $\beta$-Actin \#4970 were from Cell Signaling Technology (Danvers, MA). Antibodies to CHOP sc-7351 and ATF3 sc-188 were from Santa Cruz Biotechnology (Santa Cruz, CA).

\section{Tumor Evaluation}

Tumor response was assessed according to Response Evaluation Criteria in Solid Tumors (RECIST) [34] every two cycles.

\section{Statistical Methods}

Associations between pharmacokinetic parameters and dose level of nelfinavir were determined using an exact Jonckheere-Terpstra test for trend [35]. Comparison of pharmacokinetic parameters between two time points on paired subjects was performed with a Wilcoxon signed rank test. All p-values are two-tailed.

\section{FUNDING}

This work was supported by the intramural program of the National Cancer Institute at the National Institutes of Health.

\section{DISCLOSURE}

M.S. Ballas is employed by Bristol Myers Squibb and has research support from Astra Zeneca, Eli Lilly/ Imclone and Pfizer; serves on an advisory board for Eli
Lilly/Imclone; received an honorarium from Eli Lilly/ Imclone and Astra Zeneca; and holds stock in Bristol Myers Squibb. All remaining authors have declared no conflicts of interest.

\section{REFERENCES}

1. Fojo T and Grady C. How much is life worth: cetuximab, non-small cell lung cancer, and the $\$ 440$ billion question. Journal of the National Cancer Institute. 2009; 101(15):1044-1048.

2. DiMasi JA and Grabowski HG. Economics of new oncology drug development. Journal of clinical oncology: official journal of the American Society of Clinical Oncology. 2007; 25(2):209-216.

3. Duenas-Gonzalez A, Garcia-Lopez P, Herrera LA, Medina-Franco JL, Gonzalez-Fierro A and Candelaria M. The prince and the pauper. A tale of anticancer targeted agents. Molecular cancer. 2008; 7:82.

4. Ashburn TT and Thor KB. Drug repositioning: identifying and developing new uses for existing drugs. Nature reviews Drug discovery. 2004; 3(8):673-683.

5. Pearson JM and Vedagiri M. Treatment of moderately severe erythema nodosum leprosum with thalidomidea double-blind controlled trial. Leprosy review. 1969; 40(2):111-116.

6. Facon T, Mary JY, Hulin C, Benboubker L, Attal M, Pegourie B, Renaud M, Harousseau JL, Guillerm G, Chaleteix C, Dib M, Voillat L, Maisonneuve H, Troncy J, Dorvaux $\mathrm{V}$ and Monconduit M. Melphalan and prednisone plus thalidomide versus melphalan and prednisone alone or reduced-intensity autologous stem cell transplantation in elderly patients with multiple myeloma (IFM 99-06): a randomised trial. Lancet. 2007; 370(9594):1209-1218.

7. Rudin CM, Brahmer JR, Juergens RA, Hann CL, Ettinger DS, Sebree R, Smith R, Aftab BT, Huang P and Liu JO. Phase 2 study of pemetrexed and itraconazole as second-line therapy for metastatic nonsquamous non-small-cell lung cancer. Journal of thoracic oncology: official publication of the International Association for the Study of Lung Cancer. 2013; 8(5):619-623.

8. Goldberg SB, Supko JG, Neal JW, Muzikansky A, Digumarthy S, Fidias P, Temel JS, Heist RS, Shaw AT, McCarthy PO, Lynch TJ, Sharma S, Settleman JE and Sequist LV. A phase I study of erlotinib and hydroxychloroquine in advanced non-small-cell lung cancer. Journal of thoracic oncology: official publication of the International Association for the Study of Lung Cancer. 2012; 7(10): 1602-1608.

9. Engelman JA. Targeting PI3K signalling in cancer: opportunities, challenges and limitations. Nature reviews Cancer. 2009; 9(8):550-562.

10. Hollander MC, Blumenthal GM and Dennis PA. PTEN loss in the continuum of common cancers, rare syndromes 
and mouse models. Nature reviews Cancer. 2011; 11(4): 289-301.

11. Garofalo RS, Orena SJ, Rafidi K, Torchia AJ, Stock JL, Hildebrandt AL, Coskran T, Black SC, Brees DJ, Wicks JR, McNeish JD and Coleman KG. Severe diabetes, age-dependent loss of adipose tissue, and mild growth deficiency in mice lacking Akt2/PKB beta. The Journal of clinical investigation. 2003; 112(2):197-208.

12. Du K, Herzig S, Kulkarni RN and Montminy M. TRB3: a tribbles homolog that inhibits Akt/PKB activation by insulin in liver. Science. 2003; 300(5625):1574-1577.

13. Bellmunt J, Szczylik C, Feingold J, Strahs A and Berkenblit A. Temsirolimus safety profile and management of toxic effects in patients with advanced renal cell carcinoma and poor prognostic features. Annals of oncology: official journal of the European Society for Medical Oncology/ ESMO. 2008; 19(8):1387-1392.

14. Gills JJ, Lopiccolo J, Tsurutani J, Shoemaker RH, Best CJ, Abu-Asab MS, Borojerdi J, Warfel NA, Gardner ER, Danish M, Hollander MC, Kawabata S, Tsokos M, Figg WD, Steeg PS and Dennis PA. Nelfinavir, A lead HIV protease inhibitor, is a broad-spectrum, anticancer agent that induces endoplasmic reticulum stress, autophagy, and apoptosis in vitro and in vivo. Clinical cancer research: an official journal of the American Association for Cancer Research. 2007; 13(17):5183-5194.

15. Saag MS, Tebas P, Sension M, Conant M, Myers R, Chapman SK, Anderson R and Clendeninn N. Randomized, double-blind comparison of two nelfinavir doses plus nucleosides in HIV-infected patients (Agouron study 511). AIDS. 2001; 15(15):1971-1978.

16. Albrecht MA, Bosch RJ, Hammer SM, Liou SH, Kessler H, Para MF, Eron J, Valdez H, Dehlinger M and Katzenstein DA. Nelfinavir, efavirenz, or both after the failure of nucleoside treatment of HIV infection. The New England journal of medicine. 2001; 345(6):398-407.

17. Touzot M, Beller CL, Touzot F, Louet AL and Piketty C. Dramatic interaction between levothyroxine and lopinavir/ ritonavir in a HIV-infected patient. AIDS. 2006; 20(8): 1210-1212.

18. Sgadari C, Barillari G, Toschi E, Carlei D, Bacigalupo I, Baccarini S, Palladino C, Leone P, Bugarini R, Malavasi L, Cafaro A, Falchi M, Valdembri D, Rezza G, Bussolino F and Monini P. HIV protease inhibitors are potent anti-angiogenic molecules and promote regression of Kaposi sarcoma. Nature medicine. 2002; 8(3):225-232.

19. Bono C, Karlin L, Harel S, Mouly E, Labaume S, Galicier L, Apcher S, Sauvageon H, Fermand JP, Bories JC and Arnulf B. The human immunodeficiency virus-1 protease inhibitor nelfinavir impairs proteasome activity and inhibits the proliferation of multiple myeloma cells in vitro and in vivo. Haematologica. 2012; 97(7):1101-1109.

20. Pore N, Gupta AK, Cerniglia GJ, Jiang Z, Bernhard EJ, Evans SM, Koch CJ, Hahn SM and Maity A. Nelfinavir down-regulates hypoxia-inducible factor 1alpha and VEGF expression and increases tumor oxygenation: implications for radiotherapy. Cancer research. 2006; 66(18): 9252-9259.

21. Guan M, Fousek K, Jiang C, Guo S, Synold T, Xi B, Shih CC and Chow WA. Nelfinavir induces liposarcoma apoptosis through inhibition of regulated intramembrane proteolysis of SREBP-1 and ATF6. Clinical cancer research: an official journal of the American Association for Cancer Research. 2011; 17(7):1796-1806.

22. Shim JS, Rao R, Beebe K, Neckers L, Han I, Nahta R and Liu JO. Selective inhibition of HER2-positive breast cancer cells by the HIV protease inhibitor nelfinavir. Journal of the National Cancer Institute. 2012; 104(20):1576-1590.

23. Gupta AK, Cerniglia GJ, Mick R, McKenna WG and Muschel RJ. HIV protease inhibitors block Akt signaling and radiosensitize tumor cells both in vitro and in vivo. Cancer research. 2005; 65(18):8256-8265.

24. Pan J, Mott M, Xi B, Hepner E, Guan M, Fousek K, Magnusson R, Tinsley R, Valdes F, Frankel P, Synold T and Chow WA. Phase I study of nelfinavir in liposarcoma. Cancer chemotherapy and pharmacology. 2012; 70(6): 791-799.

25. Patterson AD, Hollander MC, Miller GF and Fornace AJ, Jr. Gadd34 requirement for normal hemoglobin synthesis. Molecular and cellular biology. 2006; 26(5):1644-1653.

26. Novoa I, Zeng H, Harding HP and Ron D. Feedback inhibition of the unfolded protein response by GADD34mediated dephosphorylation of eIF2alpha. The Journal of cell biology. 2001; 153(5):1011-1022.

27. Yao JC, Shah MH, Ito $\mathrm{T}$, Bohas $\mathrm{CL}$, Wolin EM, Van Cutsem E, Hobday TJ, Okusaka T, Capdevila J, de Vries EG, Tomassetti P, Pavel ME, Hoosen S, Haas T, Lincy $\mathrm{J}$ and Lebwohl D. Everolimus for advanced pancreatic neuroendocrine tumors. The New England journal of medicine. 2011; 364(6):514-523.

28. Jiao Y, Shi C, Edil BH, de Wilde RF, Klimstra DS, Maitra A, Schulick RD, Tang LH, Wolfgang CL, Choti MA, Velculescu VE, Diaz LA, Jr., Vogelstein B, Kinzler KW, Hruban RH and Papadopoulos N. DAXX/ ATRX, MEN1, and mTOR pathway genes are frequently altered in pancreatic neuroendocrine tumors. Science. 2011; 331(6021):1199-1203.

29. Kawabata S, Gills JJ, Mercado-Matos JR, Lopiccolo J, Wilson W, 3rd, Hollander MC and Dennis PA. Synergistic effects of nelfinavir and bortezomib on proteotoxic death of NSCLC and multiple myeloma cells. Cell death \& disease. 2012; 3:e353.

30. Brunner TB, Geiger M, Grabenbauer GG, LangWelzenbach M, Mantoni TS, Cavallaro A, Sauer R, Hohenberger $\mathrm{W}$ and McKenna WG. Phase I trial of the human immunodeficiency virus protease inhibitor nelfinavir and chemoradiation for locally advanced pancreatic cancer. Journal of clinical oncology: official journal 
of the American Society of Clinical Oncology. 2008; 26(16):2699-2706.

31. Buijsen J, Lammering G, Jansen RL, Beets GL, Wals J, Sosef M, Den Boer MO, Leijtens J, Riedl RG, Theys J and Lambin P. Phase I trial of the combination of the Akt inhibitor nelfinavir and chemoradiation for locally advanced rectal cancer. Radiotherapy and oncology: journal of the European Society for Therapeutic Radiology and Oncology. 2013; 107(2):184-188.

32. Rengan R, Mick R, Pryma D, Rosen MA, Lin LL, Maity AM, Evans TL, Stevenson JP, Langer CJ, Kucharczuk J, Friedberg J, Prendergast S, Sharkoski T and Hahn SM. A phase I trial of the HIV protease inhibitor nelfinavir with concurrent chemoradiotherapy for unresectable stage IIIA/ IIIB non-small cell lung cancer: a report of toxicities and clinical response. Journal of thoracic oncology: official publication of the International Association for the Study of Lung Cancer. 2012; 7(4):709-715.
33. Canman CE, Wolff AC, Chen CY, Fornace AJ, Jr. and Kastan MB. The p53-dependent G1 cell cycle checkpoint pathway and ataxia-telangiectasia. Cancer research. 1994; 54(19):5054-5058.

34. Therasse P, Arbuck SG, Eisenhauer EA, Wanders J, Kaplan RS, Rubinstein L, Verweij J, Van Glabbeke M, van Oosterom AT, Christian MC and Gwyther SG. New guidelines to evaluate the response to treatment in solid tumors. European Organization for Research and Treatment of Cancer, National Cancer Institute of the United States, National Cancer Institute of Canada. Journal of the National Cancer Institute. 2000; 92(3): 205-216.

35. Hollander M and Wolfe DA. 1999. Nonparametric Statistical Methods. (New York, NY: John Wiley and Sons, Inc.). 